\title{
No Substances in a Substance
}

\section{Marek Piwowarczyk ${ }^{1}$ (D)}

Received: 17 August 2020 / Accepted: 10 March 2021 /

Published online: 30 March 2021

(c) The Author(s) 2021

\begin{abstract}
In this paper I analyze the most controversial thesis of Aristotelian substantialism, namely, that substances cannot be composed of other substances. I call this position the Mereological Limitation Thesis (MLT). I find MLT valid and defend it. My argument for MLT is a version of the argument from the unicity of substantial form. Every substance can have only one substantial form, thus, if some substances compose the object $O$, then what binds them is only a set of their accidental forms (relations) and in the result thereof $O$ is not a substance ( $O$ is not informed by a substantial form). I argue against the relativization of the substantiality of forms to the level of composition by showing that substantial forms must be absolutely identityindependent. In the last section I specify the ontological status of parts of substances and argue that they are spatially distributed bundles of accidents of a compound substance itself.
\end{abstract}

Keywords Compound substances $\cdot$ Parts $\cdot$ Accidents $\cdot$ Form $\cdot$ Matter $\cdot$ Identitydependence $\cdot$ One-many problem

I should start with a metaphilosophical remark: my considerations are ontological in Roman Ingarden's sense of the word i.e. I discuss problems concerning the content of the idea of a compound substance. This means that I talk about substances as possible entities and ask under what conditions compound substances are possible. I do not want to decide which objects of our everyday and scientific experiences are substances. For me it is possible (although highly improbable) that no substances really exist. It is the task of metaphysics to examine whether this possibility is realized in our world. ${ }^{1}$ Some philosophers will be dissatisfied with the metaphilosophical status

\footnotetext{
${ }^{1}$ For Ingarden the object of ontology is the realm of pure possibilities as assigned by the content of ideas (understood by Ingarden as Platonic entities; such a presupposition is not necessary for me). In contrast to this, metaphysics concerns the realm of facts realized possibilities. In ontology we ask about the conditions of the possibility of objects and investigate their essential features and relations whereas in
}

Marek Piwowarczyk

marek.piwowarczyk@kul.pl

1 The John Paul II Catholic University of Lublin, Lublin, Poland 
of my paper but I am convinced that purely conceptual (ontological) problems are also important and in fact are indispensable parts of metaphysical thinking.

The ontological character of my considerations is also the reason why I do not refer to science. I think science may be relevant to metaphysics but is irrelevant to ontology, i.e. irrelevant to conceptual problems concerning essential relationships between such concepts as substance, identity-dependence, accident, essence, parthood and so on.

I argue that substances cannot be composed of other substances. This thesis does not automatically imply that compound substances are impossible. However, if this thesis is true, the parts of a substance should be considered as being spatially distributed bundles of a substance's accidents. The possibility of such a view depends on the possibility of the existence of a special property called extension (quantity), which is responsible for such a spatial distribution of accidents.

\section{Introductory Concepts and Remarks}

In the Aristotelian substantialism ${ }^{2}$, an individual material substance is conceived of as an entity that enjoys at least the following characteristics:

- it is a subject of accidents (properties ${ }^{3}$ ); the subject in question is not a bare substratum but has its own qualitative content called the substantial form which makes this substance what it is and which ensures the unity of this same substance;

- it endures in time although it undergoes changes, i.e. a substance is wholly present in each moment of its existence despite its loss and acquiring of new accidents ${ }^{4}$;

- it can be generated and corrupted;

- it cannot be composed of other substances;

- it is ontologically prior over entities belonging to other categories (accidents: qualities, quantities, relations, states, actions, passions etc.). This priority is often expressed in terms of the ontological independence of a substance and the concurrent ontological dependence of non-substantial entities upon a substance. What sort of ontological dependence is needed here is the object of controversy. Later on I will argue that substances are identity-independent of accidents while accidents are identity-dependent on substances.

\footnotetext{
Footnote 1 (continued)

metaphysics we investigate the real essences of things (see Ingarden, 2013, 61-83). The Ingardenian conception of ontology is close in many respects to Jonathan Lowe's metaontology (see Lowe, 2006, 3-5).

2 By Aristotelian substantialism I mean some ideal type in Max Weber's sense. Historical varieties of Aristotelianism may differ in some respects from this ideal type.

${ }^{3}$ For me accidents (properties) are abstract particulars, i.e. are inseparable aspects of a substance. Properties are not wholly present in many individuals and in this sense they are particular. Yet such particularity does not imply qualitative uniqueness.

${ }^{4}$ I think substantialism leads to presentism but I cannot argue for this thesis this paper.
} 
Ontological dependence conceived in the broader sense is a sort of existential or essential conditioning. ${ }^{5}$ Following Roman Ingarden (2013, 147-155), I distinguish existential dependence and existential inseparability. ${ }^{6}$ This distinction has not been discerned by analytical philosophers ${ }^{7}$ but I think it allows for a more precise description of the ontological status of properties. My definitions of inseparability and dependence are modified Ingardenian formulas and are as follows:

$x$ is existentially inseparable from $y$ iff it is implied by the essence of $x$ that (i.) $x$ coexists with $y$ and (ii.) $x$ together with $y$ make up a non-mereological whole i.e. a whole united by a formal relationship(s).

$x$ is existentially dependent on $y$ iff it is implied by the essence of $x$ that (i.) $x$ coexists with $y$, and (ii.) $x$ and $y$ do not make up any non-mereological whole i.e. a whole united by a formal relationship(s).

The ingredients of a non-mereological whole are not its parts in a regular sense, i.e. they are not "pieces" of the whole, but they are the abstract (in the sense related to abstraction by isolation) aspects of the whole.

Both types of existential conditioning can be mutual or unilateral, rigid or generic. The above formulas are definitions of rigid inseparability and dependence, i.e. inseparability from (or dependence on) a particular, determinate entity. By contrast, $x$ is generically dependent on entities belonging to a type $F$ iff $x$ must coexist (in the manner described above) with any entity belonging to $F$. We can define generic inseparability analogously. Neither inseparability nor dependence can obtain on their own. They must be grounded in some formal relationships or necessary relations. A formal relationship is such a reference (in the ontological sense of the Aristotelian pros $t i$ ) of one entity to another which is not a relation. ${ }^{8}$ This means that formal relationships are not some additional content existing between objects (like brotherhood or parenthood) but are forms of the immediate and (rigidly or generically) necessary coexistence of entities. I postulate them (as Roman Ingarden, Jonathan Lowe, Peter Simons, Arda Denkel and many others do) to avoid the Bradley regress. Non-mereological wholes, i.e. wholes which are united by formal relationships, can also be named "formal wholes" or "formal unities".

A formal relationship is always necessary (rigidly or generically) for at least one of its terms. Necessary relations are also possible - they are the additional content which exists between objects but such that is implied by the essences of these objects. In a whole made up of inseparable entities, formal relationships are the principles of unity - they are the "ties that bind" as Simons (2005) claims. But not all formal relationships are such ties. On the grounds of classical theism every created

\footnotetext{
${ }^{5}$ In the subsequent part of this section (except for the last three paragraphs) I use passages (in some cases modified) from my two papers: Piwowarczyk (2020b, sec. 2) and Piwowarczyk (2020a, sec. 5).

${ }^{6}$ In Polish: "niesamodzielność”; in German: „Seinsunselbstandigkeit “. Arthur Szylewicz translates this as ,non-selfsufficiency “. I decided to use ,inseparability “ to stress the condition of making up one whole.

${ }^{7}$ For standard accounts of ontological dependence see Correia (2005), Koslicki (2013), Tahko and Lowe (2016).

${ }^{8}$ See Chrudzimski (2005), Lowe (2006, 34-51), Mulligan (1998).
} 
object stands to God in the formal relationship of being created by, but this is not a relationship generating inseparability. Therefore, created objects are only dependent (rigidly and unilaterally) on God. Platonists can say the same about individual things participating in ideas.

Since inseparability may be mutual or unilateral it is neither symmetric nor asymmetric in the strict logical sense. I do not want to discuss these issues in detail. However, I want to argue for the specific thesis, very important in the context of substantialism, that if $x$ is (rigidly or generically) inseparable from $y$, then $y$ is $a t$ least generically inseparable from $x$. An inseparable entity is somehow incomplete and makes up a formal unity with another entity. Yet, notice that making up a unity seems to be symmetric. If $x$ is united with $y$, then $y$ is united with $x$. Moreover, this is a formal unity. Yet, if $y$ would be separable from $x$, then $y$ could be united with $x$ only through a relation. This would mean that $y$ makes up a mereological whole with $x$ while $x$ makes up a formal unity with $y$. This seems untenable. Thus, I think that a complement of an inseparable entity must be at least generically inseparable from this entity. It is evident that an analogical statement is not true in the case of dependence, because dependent objects are not formally united with the objects upon which they are dependent.

The transitivity of inseparability seems to be doubtful at first glance. Is a particular mass inseparable from a particular color, if the mass is inseparable from a particular substance and this substance is (generically) inseparable from the color in question? There are two objections against the positive answer. First, one could say that in this case the mass does not make up a direct unity with the color and therefore the color does not supplement the concerned mass. Second, the formal whole "mass + substance" is different from the whole "substance + color". Thus, the mass and the color do not belong to one and the same whole. They belong to different wholes which have a common part.

When it comes to the second objection, notice that in the definition of inseparability, the identity of a whole is not specified. Surely the mass, the substance and the color make up one whole (substance + mass + color) that is united by formal relationships. It is then subsequently true that the mass of the substance and the color coexist within such a whole.

The first objection is more problematic. It is true that the mass and the color are not directly united, but are united via the substance. Yet notice that the substance is not a relation between the mass and the color. The substantial subject ties together the mass and the color not because it is a relation between them, but because the subject is generically inseparable from its accidents and these accidents are rigidly inseparable from their respective subject. It is still true that the mass and the color must coexist within one whole which is not united by relations.

With this, there is one additional issue. In the case of the transitivity of inseparability, as understood above, generic inseparability is dominant over rigid inseparability. If $x$ is rigidly inseparable from $y$, and $y$ is generically inseparable from $z$, then $x$ is only generically inseparable from $z$.

Separable entities are entities which are not inseparable. Analogically, independent entities are entities which are not dependent. Separable objects can be dependent or independent. A dependent object is always separable and can be of two types: 
either it does not make up any whole with the object upon which it is dependent or the both objects compose a mereological whole - united by necessary relations (it is at least possible that there exist wholes composed of distinct but mutually dependent subjects of properties).

I also use Jonathan Lowe's concept of identity-dependence in his own formulation $(2001,149)$ :

The identity of $x$ depends on the identity of $y={ }_{\mathrm{df}}$ Necessarily, there is a function $F$ such that it is part of the essence of $x$ that $x$ is the $F$ of $y$.

This definition is equivalent to another Lowe's statement $(2001,147)$ : “To say that the identity of $x$ depends on the identity of $y$-or, more briefly, that $x$ depends for its identity upon $y$-is to say that which thing of its kind $y$ is fixes (or at least helps to fix) which thing of its kind $x$ is. (By 'fixes' in this context I mean metaphysically determines ...)." We can also say that $x$ is identity-dependent on $y$ iff the essence of $x$ contains (and not merely implies) a formal relationship to $y$. In this sense identity-dependent objects have relative essences.

Identity-dependence must be grounded in some formal relationship. This sort of ontological dependence is always unilateral and entails existential dependence or inseparability. Identity-dependence, unlike existential dependence and inseparability, cannot be generic. Remember that identity-dependent objects have relative essences. If the reference to $y$ is a part of the essence of $x$, then $x$ is rigidly identity-dependent on $y$. For, if we exchange the reference to $y$ with reference to another object, then we get a new essence, and consequently a new object. Existential dependence and existential inseparability can be generic because a relationship which grounds such dependencies is not part of the essence of a dependent object although it "flows" from this essence.

In this paper I assume that the real (spatiotemporal) world is entirely particular. Substances, accidents and substantial forms are particulars in the sense they are not literally shared; they are not wholly present in many separable objects. Of course particulars can be perfectly similar to each other. I cannot provide an expanded argument in favor of this thesis but I am apt to accept a version of Plato's reasoning that immanent universals are impossible because otherwise the objects exemplifying a universal would be inseparable (at least generically) from each other or the universal in question would be separable from itself. For me both alternatives seem to be untenable. Note that I refer to inseparability and separability as defined above, thus I do not refer to the spatial sense of these terms. Therefore my argument cannot be easily dismissed by saying that since universal accidents and forms are spatial in a different manner than individuals, they can thus be multi-located.

This declaration of particularism is important in the context of the understanding of identity-dependence. For identity-dependence seems to be very similar to (or even identical with) the relation of being individuated by. This relation is required only on the grounds of moderate realism, thus I do not need individuation. Yet in fact identity-dependence is not individuation if the latter is conceived of as particularization. That $x$ is identity-dependent on $y$ does not mean that $x$ in itself is universal and 
that the reference thereof to $y$ transforms $x$ into a full-blooded particular. That $x$ is identity-dependent on $y$ means that that what $x$ is (when is is taken in the Aristotelian kath auto predication sense) contains the reference to $y$. Consequently $x$ is not something in itself, it is always something-with-respect-to- $y$. Thus there is a subtle, but ontologically important, difference between identity-dependence and existential rigid dependence (and inseparability). In the case of sheer existential rigid dependence (and inseparability) that what $x$ is implies a relationship to $y$. However, $x$ needs this relationship to exist and not to be $x$. In contrast, when $x$ is identity-dependent on $y, x$ requires $y$ both to be $x$ and to exist. No question of individuation (in the sense of particualarization) is entangled in this issue. Thus, there is a possibly qualitatively unique object that is identity-dependent on another object.

\section{The Mereological Limitation Thesis}

The fourth thesis of substantialism - that no substance can be composed of other substances - can be named The Mereological Limitation Thesis (MLT). ${ }^{9}$ I mean the integral parts ${ }^{10}$ of any level of composition, for example: systems of organs, organs, tissues, cells, molecules, atoms, elementary particles etc. MLT is the most controversial ingredient of substantialism and has the following implausible consequences:

1. Objects composed of genuine substances are not substances (this thesis is equivalent to MLT and can be considered its alternative version).

2. Given that being a substance is equivalent to having a distinct substantial form, integral parts do not have their own substantial forms but are subordinated to the substantial form of a compound substance. This means that what they are is determined by the form of a compound substance. For example my heart is what it is not due to the distinct form: being a heart but due to my humanity.

3. It follows from 2. that integral parts are identity-dependent on a compound substance. For a form is the principle of identity of a substance (see Oderberg, 2007, 66). Such a dependence implies existential inseparability or at least existential dependence, ${ }^{11}$ so:

4. Integral parts cannot exist outside a substance composed of them. They cannot survive the decomposition of a substance and cannot be detached from it.

5. No substance can survive absorption by another substance. Such an absorption must imply destruction of the absorbed substance and generation of the new integral part of the absorbing substance.

\footnotetext{
${ }^{9}$ In contemporary metaphysics MLT is accepted implicitly or explicitly by Theodor Scaltsas (1994, 59-87, 150-154; 2015), Oderberg (2007, 65-71), Marmodoro (2013), Feser (2014, 196-204).

10 Sometimes integral parts are contrasted to metaphysical parts like form and prime matter.

11 Later I will argue that this should be inseparability not dependence.
} 
6. The exchange of parts between two substances is an intricate process: the detached part of the first substance ceases to exist and a new substance or set of substances comes into existence outside both substances which interchange their parts. Then, this new substance (substances) perishes at the moment of the absorption and the new integral part of the second substance is generated.

This view is highly counterintuitive - especially when considering the story about losing and gaining parts is incredible at least in the case of parts from lower levels of composition. As such, do we have any arguments for MLT?

\section{The Argument from the Unicity of Substantial Form}

The main argument for MLT is the argument from the unicity of substantial form. According to Aristotelian substantialism, a substantial form it is the principle of unity of a substance. Thus every substance can possess only one substantial form. Otherwise, a substance would not be one substance but many substances. Note that a form is the principle due to which a substance is what it is or, in other words: a form is the principle of identity of a substance. No object can have many identities - this is absurd. Now, if a compound object $O$ is a genuine substance, then it possesses only one substantial form. Thus its parts cannot have substantial forms, so they are not substances. The argument for the thesis equivalent to MLT mentioned above can be based on the same principle: if $O$ is composed of genuine substances, then there are many substantial forms in $O$, hence $O$ is not a substance (but rather plurality of substances). We have the dilemma: either a compound object is a substance and its parts are not, or parts are substances but a compound object is not. In any case, no substance is composed of substances nor is any substance a part of another substance.

This version of the argument is unsound. I think it is based on equivocation. The word "possess" is ambiguous in this context. First, " $O$ possesses a form" can mean " $O$ is informed by a form". Second, " $O$ possesses a form" can mean "a form can be found within $O$ ". The second meaning is broader and can be applied to cases in which a form does not inform $O$ but informs $O$ 's part. The thesis about the unicity of form concerns the first meaning: a substance cannot be informed by more than one substantial form; nothing can be a horse and a cow at the same time (nor even at different times - but this is a distinct problem). But foes of MLT do not maintain that the substantial form of a part informs a compound substance. A horse which has a heart is not itself a heart, even if the heart is a substance.

More convincing is another version of the argument: Every substance can be informed only by one substantial form which is the principle of unity of a substance. Thus any new form which is to be attached to a substance cannot be a substantial form. Hence if $O$ is composed of genuine substances qualified by their own forms, the form which is the principle of unity of $O$ is the accidental form of its parts. 
Strictly speaking, such a form is a net of relations. Thus the principle of $O$ 's unity is not a substantial form and $O$ is not a substance.

One can oppose this line of reasoning by noticing that although relations are not substantial forms of parts, the net of relations is the substantial form of $O$. The net makes $O$ what it is, so the net is the substantial form of $O$. Two objects can have the same parts successively and the configuration of parts is what makes a difference. The configuration is then the individual-making form. This view relativizes the substantial character of a form to the level of composition. A form can be accidental with respect to parts but substantial with respect to the compound object. Is such a relativization correct? I think not.

\section{The Two "Form - Matter" Distinctions}

What is the "nature" of a substantial form? Can a substantial form be a sort of relational structure that integrates the parts of a substance? Roman Ingarden distinguished nine concepts of form and matter (Ingarden, 2016, 43-52). Two of them are relevant for our considerations:

a. form and matter in the Aristotelian sense (let us call them form ${ }_{\mathrm{A}}$ and matter $_{\mathrm{A}}$ )

b. form and matter in the relational-technical sense $\left(\right.$ form $_{R}$ and matter $\left._{R}\right)$.

Ad a. An Aristotelian form is conceived of as a determiner or a qualifier-i.e. something that makes a substance what it is or how it is (what it is like). A form ${ }_{\mathrm{A}}$ that makes a substance what it is (that it is this man, this horse, this cat, this dog) is called a substantial form $\mathrm{A}_{\mathrm{A}}$, e.g. this humanity, this horseness, this felinity, this doghood etc. A substantial form $\mathrm{A}_{\mathrm{A}}$ is the principle of identity of a substance. Forms which make an object how it is (what it is like: that it is strong, gentle, red or wet) are called accidental forms ${ }_{\mathrm{A}}$, e.g. this redness, this strength, this roundness. ${ }^{12}$ Matter $_{\mathrm{A}}$ is a correlate of a form $\mathrm{A}_{\mathrm{A}}$, i.e. matter $_{\mathrm{A}}$ is something which is determined or qualified by a form $\mathrm{A}_{\mathrm{A}}$. In other words, forms $\mathrm{A}_{\mathrm{A}}$ are qualities in the very broad sense (including quantity, relations, passions, actions etc.) and matter $_{\mathrm{A}}$ is a subject or a substratum of these qualities. The principal cases of matter $_{\mathrm{A}}-$ form $_{\mathrm{A}}$ structures are: a composition of prime matter $\mathrm{A}_{\mathrm{A}}$ and a substantial form $\mathrm{A}_{\mathrm{A}}$ and a composition of a substance (substantial subject) and accidents. Accidents are accidental forms ${ }_{\mathrm{A}}$ and a substantial subject is the secondary matter ${ }_{\mathrm{A}}$ correlated to them. The substantial subject as playing the role of matter $_{\mathrm{A}}$ for accidental forms $\mathrm{A}_{\mathrm{A}}$ is not a bare substratum but has its own qualitative content: the substantial form $\mathrm{A}_{\mathrm{A}}$.

Note that these characteristics of form $\mathrm{A}_{\mathrm{A}}$ and matter $_{\mathrm{A}}$ are functional: matter $_{\mathrm{A}}$ and form $_{\mathrm{A}}$ are characterized in terms of the functions they perform. This is why the Aristotelian concept of matter should not be associated with any physical or commonsensical understanding of matter. If it would be possible (what I disbelieve) that accidents have accidents then accidents would have the matter ${ }_{\mathrm{A}}-$ form $_{\mathrm{A}}$ structure.

\footnotetext{
12 More about the distinction between accidental and substantial forms in the Aristotelian sense one can find in Feser (2014, 181-189).
} 
For example, redness would be matter ${ }_{\mathrm{A}}$ for a particular shade or brightness and such a shade or brightness would be a form $\mathrm{A}_{\mathrm{A}}$ of redness.

What is a substantialform ${ }_{\mathrm{A}}$ correlated to? A substantial form $_{\mathrm{A}}$ is the basic characteristic of a substance and is a pre-condition of having other characteristics. Thus a proper correlate of a substantial form $\mathrm{A}_{\mathrm{A}}$ must be devoid of any characteristics: it must be completely formless in itself. For, if such a correlate would have some characteristics, it should also have some substantial form ${ }_{\mathrm{A}}$ which conditions these characteristics. Such formless matter ${ }_{A}$ is called "prime matter $_{A}$ ". Of course friends of prime matter $_{\mathrm{A}}$ do not maintain it is a concrete object: it is only an inseparable ingredient of being and it cannot exist without some substantial form ${ }_{\mathrm{A}} \cdot{ }^{13}$ In other words, prime matter ${ }_{\mathrm{A}}$ is generically inseparable from substantial forms ${ }_{\mathrm{A}}$. It is easy to see that prime matter $_{\mathrm{A}}$ is reduced only to the function of being informed. Personally $\mathrm{I}$ think the concept of prime matter ${ }_{\mathrm{A}}$ is self-contradictory. Prime matter ${ }_{\mathrm{A}}$ cannot have any identity in itself, if it is supposed to receive any substantial form $\mathrm{A}_{\mathrm{A}}$ - the principle of identity. Postulating prime matter $_{\mathrm{A}}$ seems to be the result of the misinterpretation. First, note that a form $\mathrm{A}_{\mathrm{A}}$ makes an object what it is. For example a particular humanity makes Socrates what he is. It is Socrates who is human, and we do not need any additional pure receiver of the substantial form ${ }_{\mathrm{A}}$. Second, the concept of prime matter $_{\mathrm{A}}$ derives from the incorrect doctrine of a substantial change- a doctrine stated in terms of a general scheme suitable only for accidental changes. This is why a formless substratum is postulated as something which undergoes a substantial change. Yet, if prime matter ${ }_{\mathrm{A}}$ is devoid of any identity, how can it exist in successive substances, how can it survive a substantial change? Such a survival presupposes the retaining of identity. The statement that prime $^{\text {matter }}{ }_{\mathrm{A}}$ can retain its identity because it does not have any is possible only when we use a rather Pickwickian meaning of identity.

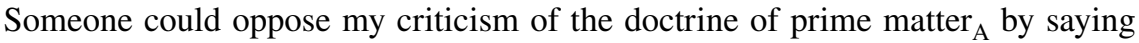
that prime matter $_{\mathrm{A}}$ does not owe its identity to a substantial form $\mathrm{A}_{\mathrm{A}}$ but enjoys primitive identity. Yet notice that in this case all forms ${ }_{\mathrm{A}}$ which can be found within a material substance are accidental with respect to prime matter ${ }_{\mathrm{A}}$ and prime matter $_{\mathrm{A}}$ turns out to be the true substantial subject. Then a substantial form A $_{\text {(particular!) }}$ cannot be understood as the principle of substantial identity and all compounds of substantial form $\mathrm{A}$ and prime matter $_{\mathrm{A}}$ are in fact so called accidental compounds which are similar in their ontological status to such objects like Socrates-smart or Coriscus-musical. Of course we still can call the compound of prime matter $_{\mathrm{A}}$ and a substantial form $\mathrm{A}_{\mathrm{A}}$ "a substance" but this is merely a terminological decision. If substances are supposed to be substantial unities and if a substantial form $\mathrm{A}_{\mathrm{A}}$ is the genuine principle of substantial identity, allegedly existing prime matter ${ }_{\mathrm{A}}$ must be devoid of any sort of identity. A substantial form $\mathrm{A}_{\mathrm{A}}$ must be the principle which transforms the identity of its correlate - in any other case such a transformation is accidental. This is, I think, the source of the paradoxical "nature" of prime matter ${ }_{\mathrm{A}}$ : it is supposed to be something but as the correlate of a substantial form ${ }_{\mathrm{A}}$ it must be nothing in itself.

\footnotetext{
${ }^{13}$ However, it is unclear why prime matter $_{\mathrm{A}}$ is inseparable (generically) from any substantial form A $_{\text {. }}$. Prime matter ${ }_{\mathrm{A}}$ has no essence which would force it to coexist necessarily with any form . $_{\text {. }}$
} 


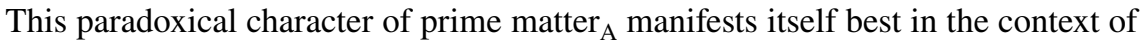
substantial change. If prime matter $_{\mathrm{A}}$ has primitive identity, then all of its transformations are in fact accidental changes - after a change prime matter $_{\mathrm{A}}$ still remains what it has been and only exchanges accidental forms ${ }_{\mathrm{A}}$. Again, we can call this a substantial change but it is only our arbitrary decision. If someone postulates a substratum which can survive a substantial change and still insists that the product of such a change is a genuine new substance (i.e. something which enjoys substantial unity), then one is forced to say that this substratum has no identity of its own because otherwise such a product product would be merely an accidental compound. A substantial change is the transformation of the identity of a substance which undergoes such a change. But this means that the substance in question must be completely destroyed and replaced by a new substance - a new substantial unity which enjoys a new identity. If it turns out that something has survived the change and retains its identity in a new being, then such a lucky survivor is in fact the substance, and no substantial change has been occurred.

Anyway, in the history of metaphysics we can find two positions: that a sub-

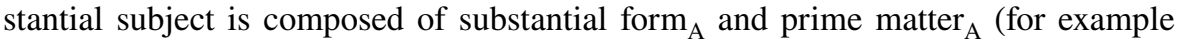
Thomism) and that a substantial subject, in abstraction from all accidents, is the substantial form ${ }_{\mathrm{A}}$ (Lowe, Ingarden and many others). I am inclined to follow the latter tradition. This option does not make all objects immaterial in the sense of "spiritual" - remember that "matter" does not have any physical connotations here. Thus for me the thesis that the substantial form $\mathrm{A}_{\mathrm{A}}$ (or essence) constitutes a subject of accidents (makes it what it is) means that the form ${ }_{\mathrm{A}}$ is a subject of accidents as considered in abstraction from them.

In Aristotelian substantialism two types of accidents are distinguished: necessary (accidentia propria, proper accidents) and contingent - the distinction between substance (or essence) and accidents is not modal (see Oderberg, 2011). Proper accidents are such accidental forms ${ }_{\mathrm{A}}$ which are conditioned solely by the substantial form ${ }_{\mathrm{A}}$. Thus, a substance must have them in all circumstances in which it can exist. Proper accidents cannot be lost nor gained. They are implied by the essence but are not contained in the essence. Will, intellect and sense powers were usually considered by scholastic philosophers as accidentia propria. By contrast, contingent accidents are partially conditioned by the substantial form ${ }_{\mathrm{A}}$ and partially by external circumstances.

Traditionally, a substantial form $\mathrm{A}_{\mathrm{A}}$ is conceived as the ultimate power of a substance and the ground (at least partial) of its accidental powers - it is the principle that determines how a substance acts and how it reacts to environmental impact. A substantial form $\mathrm{A}_{\mathrm{A}}$ also determines what accidents a substance must have in all circumstances (proper accidents) and in special conditions (contingent accidents). Thus a substantial form $\mathrm{A}_{\mathrm{A}}$ determines the possible order of changes a substance can undergo. New contingent accidents which a substance gains in some circumstances balance environmental impact upon a substance. Every substantial form $\mathrm{A}_{\mathrm{A}}$ is compatible only with a limited scope of contingent accidents. Thus in such circumstances which can be balanced only by an accident which does not belong to this scope, a given substantial form $\mathrm{A}_{\mathrm{A}}$ must be destroyed and a substance is corrupted and replaced by another substance. 
Finally, we should remember that substances are objects which enjoy a primitive identity. This means that substances are identity-independent entities. Thus a substantial form $\mathrm{A}$, which is the principle of identity, must also be identity-independent. Why we should think about substances in terms of identity-independence will be explained later.

Ad b. The matter ${ }_{\mathrm{R}}$ of object $O$ is an ensemble of $O$ 's parts and its form $\mathrm{R}_{\mathrm{R}}$ is a net of relations obtaining between parts. This form ${ }_{R} /$ matter $_{R}$ distinction can be applied only to compound objects while Aristotelian concepts also concern (if possible) mereologicaly simple things. Forms ${ }_{R}$ can be of different types: organic, mechanical, crystalline etc. Notice that considerations concerning forms ${ }_{R}$ and matter $_{R}$ cannot be reduced to standard extensional mereology since mereology neglects relations between parts.

The distinction between the two pairs of matter/form notions is much more important than it seems at first sight. In fact this is the distinction between two principal types of analysis of the object. The first is done in terms of the qualified-qualifier structure (especially the subject-properties structure if you do not believe in prime matter $_{\mathrm{A}}$ ), the second in terms of the parts - whole structure. The former is typical of metaphysics, the latter-of science. The reconciliation of them would bring metaphysics closer to science and vice versa. Anyway, there is a purely conceptual problem concerning of whether these two structures can coincide in one being and, if they can, how they condition each other. Of course I cannot solve this problem at this time so I must limit my considerations to a few remarks relevant to the main topic:

As I said, the composition of a substantial subject and an accidental form A $_{\mathrm{A}}$ is sometimes called an accidental unity or an accidental compound (Lewis, 1982). By no means are accidental compounds distinct substances. This category is closer to the contemporary category of states of affairs. Socrates and his corpulence do not make up any substance but they constitute the accidental compound "corpulent Socrates" or the state of affairs "that Socrates is corpulent". What is the ontological status of accidental compounds or states of affairs? This status is determined by the ontological status of substances (substantial subjects) and accidents. As I said, this status is expressed in terms of ontological dependence/independence in the broader sense.

It is easy to explain the priority of substances over contingent accidents: the latter are rigidly inseparable from substances but substances are only generically inseparable from accidents. Notice that accidents cannot be merely generically inseparable from a substance because otherwise they would share the same existential status as substances (I still mean substantial subjects). Imagine substantial subjects $S_{1}$ and $S_{2}$ and accidents $A_{1}, A_{2}$. Let us assume $S_{1}$ and $S_{2}$ are generically inseparable from, accordingly $\mathrm{A}_{1}$ and $\mathrm{A}_{2}$, and vice versa. Then the substantial subjects can survive an exchange of accidents and accidents can survive an exchange of substantial subjects. The world can contain accidental compounds $\left(\mathrm{S}_{1}, \mathrm{~A}_{1}\right)$ and $\left(S_{2}, A_{2}\right)$ or $\left(S_{1}, A_{2}\right)$ and $\left(S_{2}, A_{1}\right)$, so substantial subjects and accidents turn out to be equally basic bricks of reality. If we want to construe some kind of independence theory of substance (of the substantial subject) then we must make substantial subjects stronger than accidents. 
The explanation in terms of inseparability does not work in the case of proper accidents. For they are mutually rigidly inseparable from a substance. Proper accidents cannot be lost because they "emanate" (the favorite term of Thomas Aquinas) from the essence.

Thus we must seize for another type of dependence: the identity-dependence. All accidents are identity-dependent on their substance but the substance is identity-independent of accidents although it is, rigidly or generically, inseparable from them. Identity-dependence consists in having a relational essence. Of course I do not here mean relations but formal relationships. The essence of an accident contains the relationship in which an accident stands to a substance. The essence of a substance does not contain any relationships in which it stands to accidents. In this sense (and only in this sense!) the essence of a substance is absolute (nonrelational). In other words: a substance stands in some necessary relationships to accidents but these relationships do not determine the individual identity of a substance.

As I said, for me a substantial subject (a substance in abstraction from accidents) is identical with its essence and the latter is identical with the substantial form $_{\mathrm{A}}$. Even if prime matter $_{\mathrm{A}}$ does exist (something that I disbelieve), it could not determine what a substance is because prime matter ${ }_{A}$ in itself (in abstraction from any substantial form $_{\mathrm{A}}$ ) is formless, and thus devoid of any identity. Anyway, prime matter $_{\mathrm{A}}$ would be subordinated to a form $\mathrm{A}_{\mathrm{A}}$ as a pure receiver of a form $\mathrm{A}_{\mathrm{A}}$ - and by no means would a substantial form $\mathrm{A}_{\mathrm{A}}$ be identity-dependent on prime matter $\mathrm{A}_{\mathrm{A}}$. Thus a

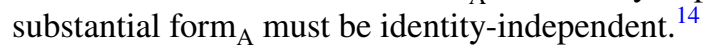

Since accidental compounds and states of affairs are what they are due to some accidents and the substances qualified by them, accidental compounds are either identity-dependent on substances or are nothing over and above substances as modified by accidents.

Relations are accidents. Even if there are necessary relations in which some substances must stand to each other, they have the status of proper accidents. Such accidents "flow" or "emanate" directly from the essence of a thing, unlike contingent accidents which are conditioned by the essence and by the external environment as well. Thus all relations obtaining between substances are identity-dependent on them. Now if $O$ is composed of some substances, the form $\mathrm{R}_{\mathrm{R}}$ of $O$ is a net of relations. Such a form $\mathrm{R}_{\mathrm{R}}$ is identity-dependent on the bearers of relations so it cannot be a substantial form $\mathrm{A}_{\mathrm{A}}$ and in consequence $O$ is not a substance. $O$ is only a relational state of affairs and as such is either identity-dependent on substances and relations or is just identical with these substances linked by relations. $O$ cannot survive a change of any relations belonging to its form $\mathrm{R}_{\mathrm{R}}$ nor can it lose (or acquire) new parts: in such cases we simply have different relational states of affairs.

On the other hand, if a compound object $O$ is a genuine substance then it is united by a substantial form A . But a substantial form A $_{\mathrm{A}}$ is a peculiar unifier. It unifies parts (or abstract aspects) of a substance because everything which can be found within

\footnotetext{
$\overline{14}$ Unless we distinguish a thin and a thick substance (Pasnau, 2011, 99-102), some problems with iden-

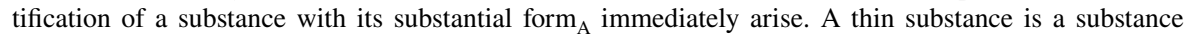
conceived as a mere subject of accidents, a subject as grasped in abstraction from them. A thick substance is a subject modified by accidents, i.e. considered in its relationships to accidents. What I identify with a substantial form $_{\mathrm{A}}$ is a thin substance.
} 


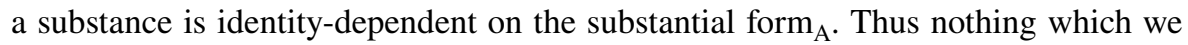
can find within a substance is a substance. Essences of all parts of a substance are determined in their identities by its substantial form $\mathrm{A}_{\mathrm{A}}$. The parts also stand in some relations to each other but these relations are assigned by the substantial form $_{\mathrm{A}}$ and are identity-dependent on it.

But why do parts have to be identity-dependent on substances? Why is it impossible to preserve both: the identity-independence of substances and the identity-independence of parts? Why should we define substances in terms of identity-independence at all? I admit that the above considerations about ontological priority of substances may seem to be a bit artificial and ad hoc. Thus we need further analysis.

\section{Substantialism and the One - Many Problem}

Following some ideas of Theodore Scaltsas (1994, 59-87, 150-154; 2015) we can consider substantialism as a solution to the one-many problem: how can one reconcile the unity of a compound object with the plurality of its parts. Substantialists can ask: under what conditions is it possible for a substance to have parts? Substantialists are convinced that the one-many problem can be solved only if compound objects are substances, i.e. objects which owe their unity to their own essences. In this section I am going to argue for the thesis that a compound object is a substance iff:

(I) the compound object is not identical with a plurality of related (or even interdependent or mutually inseparable) parts;

(II) parts are identity-dependent on the compound object and

(III) parts are rigidly inseparable from the compound object and

(IV) the compound object is at least generically inseparable from its parts.

Ad (I) Consider the most (in)famous question associated with the one-many problem: is a compound object something over and above its parts? Of course there are two possible answers. If one says: no, then a compound object is identical with its parts: a compound object is just its parts. This means that a compound object is not one object (grammar deceives us) but a plurality of objects. Notice that we discuss what a compound object is, i.e. we discuss the problem of the identity of a compound object. If a compound object is nothing over and above its parts then it is identical with the parts and composition is understood as identity. Then, a compound object can have only purely additive properties (like mass, dimensions etc.) or purely structural properties (like having such and such parts) which in fact are reducible to properties of parts. Scaltsas calls such an object "an aggregate" and this term has a very long tradition. The essence of an aggregate is being a plurality of such and such objects. There is nothing within an aggregate which could make it 
different than its parts, no principle which could raise it over and above its parts. In contrast, a substance is something which enjoys an essential unity. Thus aggregates cannot be substances.

One could notice that an aggregate is mere plurality because it is insensitive to relations obtaining between its parts. But it is possible that there are such objects for which relations really count. Scaltsas names these objects "related wholes". Is such an object anything over and above its parts? At first sight it seems to be so. But we think so because we usually compare a related whole to an aggregate. Of course there is something essential for a related whole which is not essential for an aggregate composed of the same objects: this being relations. But this only means that a related whole is a plurality of objects linked by relations. This still concerns plurality. ${ }^{15}$ The essence of such a thing is simply composed of parts related in some way. A related whole is a relational state of affairs which is nothing over and above parts and relations. Of course related wholes are special relational states of affairs i.e. they constitute only a subset of the set of relational states of affairs. Not all relations are whole-making relations. Parts must somehow hold together or fit to each other. The nature of this holding together is a topic for a distinct paper. Anyway, related wholes are pluralities of objects standing in some relations.

One can be in opposition here by saying that a related whole is one object due to special relations or to special interactions between parts; a whole is not an aggregate of disconnected entities, but its parts are properly tied by proper (whole-making) relations (or interactions) and this is why such parts compose one object and not an aggregate or a non-holistic relational state of affairs. I think this objection is based on a confusion of the two meanings of "one" or "unity". Of course a related whole is one object in the sense that its parts are not isolated but are somehow connected, united in a stronger or weaker way. Parts of a related whole are held together, somehow fit to each other. Yet "one" or "unity" in the one-many problem, insofar as it is expressed by the "something over and above" question, has a different meaning. The one-many problem does not primarily concern the connectedness between many beings but consists in the question of whether these beings form up another being irreducible to the plurality of objects or to the plurality of related objects. "One" refers to an object that enjoys a new identity. The "one" from "the one-many problem" is a new object that stands in some relationships with some plurality of other objects (parts). Therefore the problem of identity is entangled in the one-many problem and we cannot limit ourselves only to relations or even to existential dependencies between parts.

Consider the strongest connectedness between entities: existential dependence or even inseparability. If the entities that compose some whole are mutually inseparable from each other, the whole itself is the result of the fact the parts thereof mutually satisfy their demands for being supplemented. But if we cannot find within an object anything besides its parts and the relationships between them, then a whole is nothing over and above the plurality of mutually inseparable entities. Parts of such

15 Thus attempts to solve the problem of unity in terms of the relations between parts (Fine, 1999, Johnston, 2006) are invalid. 
a whole cannot exist outside the whole not because they are inseparable from the alleged whole as a new object but because they are inseparable from other parts. We do not have to refer to the whole at all. This is why Peter Simons's nuclear bundle theory is not a hidden substantialism but a very sophisticated bundle theory (Simons, 1994, 2005). If a compound object is nothing over and above its parts, the relations (or even formal relationships) between a part and the compound object are reducible to the relations (or formal relationships) between this part and other parts. When we abstract (I mean abstraction by isolation) from all parts, we are left with noting which could be a term to which parts are related. Thus if a compound object is nothing over and above its mutually inseparable parts we cannot say that parts are inseparable from a compound object. The unity of substance is guaranteed by its essence, but if a whole is just the plurality of inseparable objects, then the unity of such a whole "flows" from the essences of the inseparable objects in question - to repeat: objects inseparable with respect to each other. Therefore, such a whole is not a substance. It is a sort of intellectual illusion to think that wholes composed of mutually inseparable (or dependent) parts enjoy some ontological priority over these parts. In fact such wholes are these parts as taken together and linked by stringent relationships.

Ad (II) We have just seen that a compound substance must be different than the plurality of parts even if the parts are mutually dependent on or inseparable from each other. Now, when we introduce a compound substance as something besides its parts we still have the problem of plurality because the only thing we have done consists in a replacement of the plurality of parts with the plurality of parts + a compound substance. ${ }^{16}$ That such a model does not solve the problem of unity is evident if we realize that it is a general scheme for some types of dualism (mental substance dualism, for instance). All crucial problems which haunt dualism are in a germ contained in this model. For example the lack of essential unity manifests itself as the lack of psychophysical unity (as emphasized in Koons, 2014, passim). In such a case parts can only constitute the closest environment of a compound object - and only in this way the latter "has" parts.

We can solve the one-many problem only by means of some kind of subordination of the plurality of parts to the unity of a compound object. Again, this subordination cannot be dependence or inseparability because then we only replace the plurality of interdependent or mutually inseparable parts with the plurality of parts + a compound object (mutually dependent or inseparable). Remember that we agreed that the plurality of inseparable parts is still a plurality, so it would be unclear why parts + a compound object is not a plurality even if parts and a compound object are interdependent or inseparable. We must search for another kind of subordination which will allow for us to reconcile the unity of a compound object with the plurality of parts. Notice that we have to reconcile one identity of a compound object with the many identities of its parts without eliminating any of these identities. The unity which is needed is the unity of the object with respect that that what it is (its essence). Thus the subordination in question must concern this aspect - the

\footnotetext{
16 Analogously, Kathrin Koslicki's doctrine of structure (Koslicki, 2008, 2018), where the unifying structure is understood as the additional object, cannot resolve the onemany problem.
} 
unity in question is the unity of essence. An object is one if it is "covered" by one essence, so to speak. If an object is simple, there is no problem with such a "covering". But if an object has parts then its essence can cover the whole object only if essences of parts contain a reference to the essence of a compound object. This way a compound object is "permeated" by one identity (Oderberg, 2007, 70). Speaking a bit artificially: if a compound object is one "self" then parts cannot be absolute in their "selves" but must be subordinated to the compound object just in the aspect of "being self". A subordination merely in other aspects (of existence, of power etc.) is insufficient. But all this means that the identity of parts must be dependent on the identity of a compound object. Since identity-dependence is always unilateral, a compound substance must be identity-independent of its parts.

Ad (III) I said in Sect. 2 that identity-dependence implies rigid existential inseparability or rigid existential dependence. Now we must decide which of these two possibilities is realized in the case of substances and their parts. I think this is quite an easy task: it is obvious that a compound substance must form up some unity with its parts. Moreover, this unity must be direct. It cannot be mediated by accidental relations (even if these relations are proper accidents). Thus, the unity of a compound substance with its parts must be based on formal relationships what leads us to the conclusion that parts are rigidly inseparable from a compound substance.

Ad (IV) In Sect. 2 I also tried to show that inseparability is in a specific sense mutual; i.e. if $x$ is (rigidly or generically) inseparable from $y$, then $y$ is at least generically inseparable from $x$. Since parts are rigidly inseparable from a compound substance, the latter is at least generically inseparable from its parts. It is not my intention to decide whether there are such substances that are rigidly inseparable from some of their parts. But even in such cases a compound substance is still ontologically prior over parts because parts are identity-dependent on a compound substance. Notice also that given the transitivity of inseparability, parts of a substance are at least generically inseparable from each other.

Now consider what makes a compound substance different from its parts and the relations between them. It must be something which is left when we have abstracted (of course this is only a mental operation) from all parts. The factor in question is the essence of a compound substance. On the ground of my version of substantialism, this factor is identical with a substantial form ${ }_{\mathrm{A}}$. If a compound substance is something over and above its parts and the relations between them, the essence of a compound substance neither is its parts nor is it parts connected by relations, nor is it a net of relations. Yet remember that the essence is in fact a substantial subject, i.e. it is a substance as considered in abstraction from accidents. Thus we reach a paradoxical thesis, that a compound substance is in a sense simple. It is the paradox which Plato already was aware of in Theaetetus (203-206). ${ }^{17}$ In the passage called Socrates' Dream Plato maintains that if a whole is not identical with parts it must be a "simple form". One can take this as a thesis excluding the possibility of compound substances. Yet only the possibility that composition is identity is excluded. A compound substance is simple only in this sense that its essence is

$\overline{{ }^{17} \text { See also Harte }(2002,32-47)}$. 
simple or, in other words, a compound substance is simple when it is considered as a substantial subject. A compound substance, as something over and above its parts, can have parts only if they lie beyond its essence. The question is in what sense the compound substance has parts. We will consider this in the next section.

Now we can answer the question of whether the substantiality of a substantial form $_{\mathrm{A}}$ can be relativized to the level of composition. The substantiality of a substantial form $_{\mathrm{A}}$ is its ability to make something a substance - a substance is really a substance due to its substantial form $\mathrm{A}_{\mathrm{A}}$. It endows a substance with the essential unity. This sort of unity is grounded in the identity-dependence of all parts upon the compound substance and in the concurrent identity-independence of substance with respect to its parts. Thus the substantial form ${ }_{\mathrm{A}}$ of the compound substance must be identity-independent of all its parts. Therefore the substantiality of a substantial form $_{\mathrm{A}}$ cannot be relativized to the level of composition.

\section{The Ontological Status of Parts of Substances}

The fundamental problem of this view, besides those already mentioned in Sect. 2, is that a compound substance is not composed in the regular sense of the word. As I said, a compound substance considered as a subject of accidents is mereologicaly simple. In what sense does a substance have parts which are identity-dependent on it? The identity-dependence thesis concerns not only integral parts but must be applied to all aspects, except the essence, which can be distinguished within a substance. Indeed the identity-dependence thesis works perfectly in the case of accidents.

If a substance is something over and above accidents it is not a bundle of them but is something which is left when we have abstracted from all accidents - it is a subject of accidents. A substance is not the whole: "subject+accidents". A substance is a subject modified by accidents. Accidents are not beings on par with a subject but are the ways how a subject is, they are forms ${ }_{A}$ in which a subject exists. Socrates is not a particular human being in a pure state, but he is a male, corpulent and wise human being. But he is not the non-mereological whole: "human + masculinity + corpulence + wisdom". Socrates' accidents are forms ${ }_{\mathrm{A}}$ in which his humanity (his essence) "expresses" itself; accidents modify his humanity by giving it some "figure" or "shape". They are the ways how a particular substance is and this is the reason why they are identity-dependent on a substance (e.g. Socrates as a human being). Accidents are not beings but something of a being and this "of" belongs to their essences - accidentia non sunt entia sed entis.

Analogously, we should say that a compound substance is not identical with its parts, with parts-cum-relations, nor with the whole "subject (essence) + accidents + parts + relations between parts". The compound substance is the subject itself and the parts thereof are not additional beings surrounding it but the parts somehow "express" the subject. Parts should be understood as the ways how a substantial subject "manifests" itself, ways how it is. Thus, parts of a substance must also be entis and not entia.

But in this, do not we reduce the "compound object - parts" structure to the subject-properties structure and implicitly agree that substances have no parts at all? 
All we can do to avoid such a reduction is to consider the parts of a substance as being spatially distributed bundles of its accidents. Parts are neither a subject of accidents nor a single accident. Parts are spatially distributed bundles of accidents but the proper subject of these accidents is a compound substance (Ingarden, 2016, 125-127). Thus, parts of a substance have no essence on their own. For example, the ability to pump blood is ultimately the function of the organism performed by it at some place it occupies.

What is responsible for this spatial distribution? It cannot be space as existing independently of a substance. It must be another accident of a substance - traditionally named "quantity" or "extension" (see Pasnau, 2011, 279-299). It was understood not as a determinate magnitude or dimension but as a system of determinable "places". A quantity "stretches" a subject, it is the fundamental proper accident of a material substance - the fundamental way how such a substance is. A substance modified by quantity has other accidents which determine the aforementioned "places" and therefore are spatially distributed. Notice that quantity is also identitydependent on a substance; it is a sort of "private" space of a substance. Thus, accidents distributed this way belong essentially to a substance.

One could still have doubts as to whether such "parts" are genuinely parts. For we usually think of parts as at least being separable (and in most cases: independent) objects. But if all accidents are inseparable from a substance, then, given the transitivity of inseparability, accidents are also inseparable (generically or rigidly) from each other. This also concerns the determinable places constituting private extension. A substantialist could respond that integral parts do not have to be separable but must merely lie outside each other. But such lying outside each other seems to be a relation and not a formal relationship. Therefore, the terms of such a relation must be separable. This is a serious problem for the concept of the private space of a substance, but I cannot analyze this issue in this paper.

In order to see that the thesis about the identity-dependence of parts on a compound substance is a necessary ingredient of the solution to the one-many problem let us briefly analyze (in light of the above considerations) Robert C. Koons's doctrine of Parts as Sustaining Instruments (PASI) (Koons 214, 171-176; 2018). Koons is right when postulating that a compound substance and its parts should be somehow interdependent (in different aspects). According to PASI, parts depend on a compound substance (Koons says: on a whole) with respect to their powers; i.e. some of parts' powers are at least partially grounded in the powers of a compound substance. Subsequently, parts exercise their powers to sustain a compound substance in existence. Koons is convinced that his model of substance's action upon parts differs from the dualistic interactionist model because "the whole acts upon a part only through another part. The whole acts because it has a part capable of acting in a certain way, and the part acts or is acted upon because it plays a certain 
role in the constitution of the whole" (Koons, 2014, 172). Up to this point PASI is acceptable also on the ground of my view of substance. However, we can still ask what is the ontological status of a compound substance and its parts and exactly which role a part plays in the constitution of a compound substance.

As we have seen in Sect. 5, we must exclude these senses of "constitution" which imply that a compound substance is the plurality of parts-even if parts are supposed to be dependent on or to be inseparable from each other. A compound substance must be something which is left if we abstract from all its parts and the relations (or relationships) obtaining between them. Otherwise there is no difference between a part's own action and a substance's acting through a part and no difference between a part's dependence on a compound substance and a part's dependence on other parts. ${ }^{18}$

Now if we assume that a compound substance is distinct from all parts taken together, we should consider what it means that a compound substance acts through its parts. To avoid the interactionst dualism, acting through cannot be conceived in terms of a previous regular action exerted by a compound substance upon its parts. By a regular action I mean action as one of Aristotelian accidents. Thus the acting through in question is not similar to my acting with a knife, for example. Why? Notice that when I am acting with a knife upon a tomato, there are two subjects of two actions. The first subject is me who is holding and moving the knife. The second subject is the knife which is slicing the tomato. In fact, when we focus only on the physical aspects of the situation, $I$ am not slicing the tomato $-I$ am not even touching it. But when I am kneading dough with my hands, this is really me who is kneading. Thus in the holistic approach to compound substances, the statement that a substance acts through its parts must be understood as a statement that emphasizes that a substance itself is a subject of action although this action is being done through parts.

Under what conditions can we reconcile the requirement that a substance itself is a subject of action with the requirement that an action is mediated by parts? Only by denying that substance's parts are subjects of action. To be a subject of action also means to be a subject of a power which is correlated with this action as its source. Thus parts cannot be subjects of such powers. What then are parts if they are not subjects of actions and of powers, and if, despite this fact, an action is nonetheless being done through parts? Parts can be only groups of powers (and other accidents), thus belonging to a compound substance itself and located in some sectors of a substance's extension. A compound substance acts thorough a part because a part is a bundle of the substance's accidents placed in some locus of the substance's quantity - and this is the role of a part in the constitution of a substance. A substance still acts through parts and does not act directly because a substance is not its parts

\footnotetext{
18 The same objection can be posed to William Jaworski's conception of structure (Jaworski, 2016). According to Jaworski unifying structure is not a relation obtaining among parts but obtaining between parts and a whole. Thus we can ask about the ontological status of a whole and about the role of parts in the constitution of a whole. Jaworski implicitly maintains (while criticizing Oderberg) that parts and a whole are mutually identity-independent. Thus, mutatis mutandis, my criticism of Koons can also be applied to Jaworski's doctrine.
} 
per essentiam. But this is still the action of substance itself because the substance is a subject of powers which can be found within parts.

Thus even a model in which parts essentially must have some powers, and parts can have these powers only within some compound objects, cannot ensure the substantial unity of a compound object unless we deny that parts are subjects of these aforementioned powers. Otherwise, parts are real agents and the compound object does not act although it grounds powers of parts.

Hence, the PASI doctrine and all doctrines of substantial unity which are (at least partially) formulated in teleological terms or in terms of the subordination of parts' powers to the power of a compound substance (e.g. Rea, 2011) can work only if they are associated with the thesis of the identity-dependence of parts on the compound substance.

In accordance with my intention expressed at the beginning I have not referred to science. But one general remark is nonetheless important. It is very probable that elementary particles are not substances. But this does not necessarily undermine substantialism. It is still possible that substances are the most fundamental entities in the world and that elementary particles exist only as parts of some substances. In such a situation, elementary particles are not the subjects of properties that enjoy primitive identity but are spatially distributed bundles of accidents (qualities, potencies, quantities, processes) which inhere in compound substances and are identity-dependent on them. ${ }^{19}$ The exchange of parts between substances should then be conceived rather as interactions which lead to the destruction and origination of groups of accidents in interacting substances. Such a view is at first sight possible in pluralistic versions (many animate and inanimate substances or many animate and one inanimate substance) and in a monistic version (the whole world as one substance). ${ }^{20}$ However, pluralistic versions face the problem how to build a common space occupied by many substances from many private spaces occupied by single substances.

Acknowledgements The project is funded by the Minister of Science and Higher Education within the program under the name "Regional Initiative of Excellence" in 2019-2022, project number: 028/ RID/2018/19, the amount of funding: 11742500 PLN.

Open Access This article is licensed under a Creative Commons Attribution 4.0 International License, which permits use, sharing, adaptation, distribution and reproduction in any medium or format, as long as you give appropriate credit to the original author(s) and the source, provide a link to the Creative Commons licence, and indicate if changes were made. The images or other third party material in this article are included in the article's Creative Commons licence, unless indicated otherwise in a credit line to the

\footnotetext{
19 My analysis of compound substances seems to be in disagreement with the possibility of transplantation (I mentioned this in Sect. 2) and other biological facts (the existence of live cells cultures). However, remember that my considerations are ontological - I do not decide which objects are substances. If one believes that compound substances exist and they must meet such strong requirements as were specified in the paper, and if one thinks organisms and live cell cultures are compound substances, then one must also swallow the bitter consequence that organs and single cells are not substances and cannot survive the detachment (transplantation should then be conceived of as is sketched in Sect. 2, p. 6). One can also accept the reverse strategy: that organisms and cell cultures are only relative wholes. Anyway, neither science nor commonsense have the tools to decide which objects are substances.

20 See Schaffer (2010)
} 
material. If material is not included in the article's Creative Commons licence and your intended use is not permitted by statutory regulation or exceeds the permitted use, you will need to obtain permission directly from the copyright holder. To view a copy of this licence, visit http://creativecommons.org/licen ses/by/4.0/.

\section{References}

Chrudzimski, A. (2005). Internal, external and intra-individual relations. Axiomathes, 15, 487-512.

Correia, F. (2005). Existential dependence and cognate Notions. PhilosophiaVerlag.

Feser, E. (2014). Scholastic metaphysics. EditionesScholasticae.

Fine, K. (1999). Things and Their parts. Midwest Studies in Philosophy, 23, 61-74.

Harte, V. (2002). Plato on parts and wholes: The Metaphysics of structure. Clarendon Press.

Ingarden, R. (2013). Controversy over the existence of the world. Volume I. Translated by Arthur Szylewicz. Peter Lang.

Ingarden, R. (2016). Controversy over the existence of the World. Volume II. Translated by Arthur Szylewicz. Peter Lang.

Jaworski, W. (2016). Structure and the metaphysics of mind: How hylomorphism solves the mind-body problem. Oxford University Press.

Johnston, M. (2006). Hylomorphism. The Journal of Philosophy, 103, 652-698.

Koons, R. (2014). Staunch vs. faint-hearted hylomorphism: Toward an Aristotelian account of composition. Res Philosophica, 91, 151-177.

Koons, R. (2018). Forms as simple and individual grounds of things' natures. Metaphysics, 1, s. 1-11.

Koslicki, K. (2008). The structure of objects. Oxford University Press.

Koslicki, K., et al. (2013). Ontological dependence. An opinionated survey. In B. Schnieder (Ed.), Varietes of dependence: Ontological dependence, grounding, supervenience, response-dependence (pp. 31-64). PhilosophiaVerlag.

Koslicki, K. (2018). Form, matter, substance. Oxford University Press.

Lewis, F. A. (1982). Accidental sameness in Aristotle. Philosophical Studies, 39, 1-36.

Lowe, E. J. (2001). The Possibility of metaphysics. Clarendon Press.

Lowe, E. J. (2006). The four-category ontology. A metaphysical foundation for natural science. Clarendon Press. Marmodoro, A. (2013). Aristotle's Hylomorphism without Reconditioning. Philosophical Inquiry, 37: s.5-22.

Mulligan, K. (1998). Relations - through thick and thin. Erkenntnis, 48, 325-353.

Oderberg, D. (2007). Real essentialism. Routledge.

Oderberg, D. S. (2011). Essence and properties. Erkenntnis, 75, 85-111.

Pasnau, R. (2011). Metaphysical themes 1274-1671. Clarendon Press.

Piwowarczyk, M. (2020a). The ingardenian distinction between inseparability and dependence: Historical and systematic considerations. Horizon, 9, 532-551.

Piwowarczyk, M. (2020b). Two models of the subject-properties structure. Axiomathes, 30, 371-390.

Rea, M. C. (2011). Hylomorphism reconditioned. Philosophical Perspectives, 25, 341-358.

Scaltsas, T. (1994). Substances and universals in Aristotle's metaphysics. Cornell University Press.

Scaltsas, T. (2015). Substantial holism. Philosophical Inquiry, 39, 146-163.

Schaffer, J. (2010). Monism: The priority of the whole. Philosophical Review, 119, 31-76.

Simons, P. (1994). Particulars in particular clothings: Three trope theories. Philosophy and Phenomenological Research, 54, 553-575.

Simons, P. (2005). The ties that bind: What holds individuals together?. In K. Trettin (Ed.), Substanz. Neue Überlegungen zu einer klassischen Kategorie des Seienden (pp. 229-244). Klostermann.

Tahko, T. E., \& Lowe, E. J. (2016). Ontological dependence. In: E.N. Zalta (Ed.), The Stanford encyclopedia of philosophy. https://www.plato.stanford.edu/archives/win2016/entries/dependence-ontol ogical/. Accessed 21 March 2020.

Publisher's Note Springer Nature remains neutral with regard to jurisdictional claims in published maps and institutional affiliations. 